\title{
MICTURATING CYSTO-URETHROGRAPHY IN THE INVESTIGATION OF ENURESIS
}

\author{
BY \\ O. D. FISHER and W. I. FORSYTHE* \\ From the Department of Child Health, The Queen's University, Belfast
}

(RECFIVED FOR PUBI.ICATION MAY 3, 1954)

Enuresis is an important human problem. The persistence of the disability is regarded with despair by parents, while the patients' distress and embarrassment are difficult to assess. In spite of investigations and treatment by paediatricians, urologists and psychiatrists there is still no reliable cure.

During a period of post-graduate study in Stockholm one of us became interested in a new cysto-urethrographic technique in process of development by Kjelberg and Rudhe. We considered that the technique might, with modification, be a valuable means of investigating cases of persistent enuresis. The simple cysto-urethrographic technique described below is largely due to the inspiration and help provided by our Swedish colleagues. Examination of the urinary tract by ordinary methods does not, as a rule, reveal any abnormality, but this method of investigation has shown that there is in fact a surprisingly high incidence of organic abnormalities in enuretic children.

Enuresis may be defined as the involuntary discharge of urine and it assumes clinical importance in a child over 3 years of age. It is usually nocturnal but may be either diurnal and nocturnal, or diurnal alone. The incidence of enuresis in childhood varies with many factors such as age, environment, heredity, legitimacy, etc. Sheldon (1944) in a series of 5,000 children from residential homes between 5 and 10 years of age reported $5 \%$ to be suffering from enuresis. Thorne (1944) studied 1,000 army recruits and found that $16 \%$ gave a history of enuresis after 5 years of age. Despert (1944) showed that of 1,000 unselected children between 4 and 12 years of age enuresis was present in $26 \%$. These figures show that enuresis occurs in 5 to $25 \%$ of children between the ages of 4 and 12 years. From an examination of army recruits the incidence of enuresis in adult males was reported by Cohen (1947) to be as high as $2.5 \%$ in U.S. army recruits. It is reasonable to assume therefore that as the majority of enuretic children recover, their condition is functional in origin. The remainder, which form about $10 \%$, persist and are likely to have some organic disorder.

Most paediatric textbooks infer that organic disease can be excluded if a careful history is taken and an adequate examination of the patient and the urine made; on the other hand, some textbooks advise examination by a urologist if the enuresis fails to improve with treatment.

It is our experience that in spite of an adequate history and clinical examination the diagnosis of abnormalities of the urinary system is seldom possible unless special investigations, such as micturating cysto-urethrography, are undertaken. Furthermore, such investigations will lead to the earlier diagnosis of urological conditions which, if untreated, may give rise to a far more serious condition than the initial symptom of enuresis.

\section{Investigation of Persistent Enuresis}

A study of 135 children with persistent enuresis has been undertaken; all these children were 5 years of age or older and their condition had not responded to at least three months' intensive medical and/or psychiatric treatment. In the investigation of these patients special attention was paid to the history, e.g. age of onset, whether nocturnal, diurnal, or nocturnal and diurnal. The presence of frequency, urgency, straining or dribbling was noted and details of toilet training, attempts at cure, and the parents' and patients' attitude to the condition were determined. The child's development and progress at school were assessed. Attention was paid to the presence or absence of faecal incontinence. The incidence of enuresis in parents and siblings was recorded.

As part of a full clinical examination particular attention was paid to the following: the presence or absence of an enlarged bladder; malformation of the external genitalia; motor and sensory disturbances and the tone of the anal sphincter. The act of micturition was observed, a catheter specimen of

* Holder of a Cow and Gate travelling scholarship at Professor Wallgren's Clinic at Stockholm, 1952-53. 
MICTURATING CYSTOURETHROGRAM

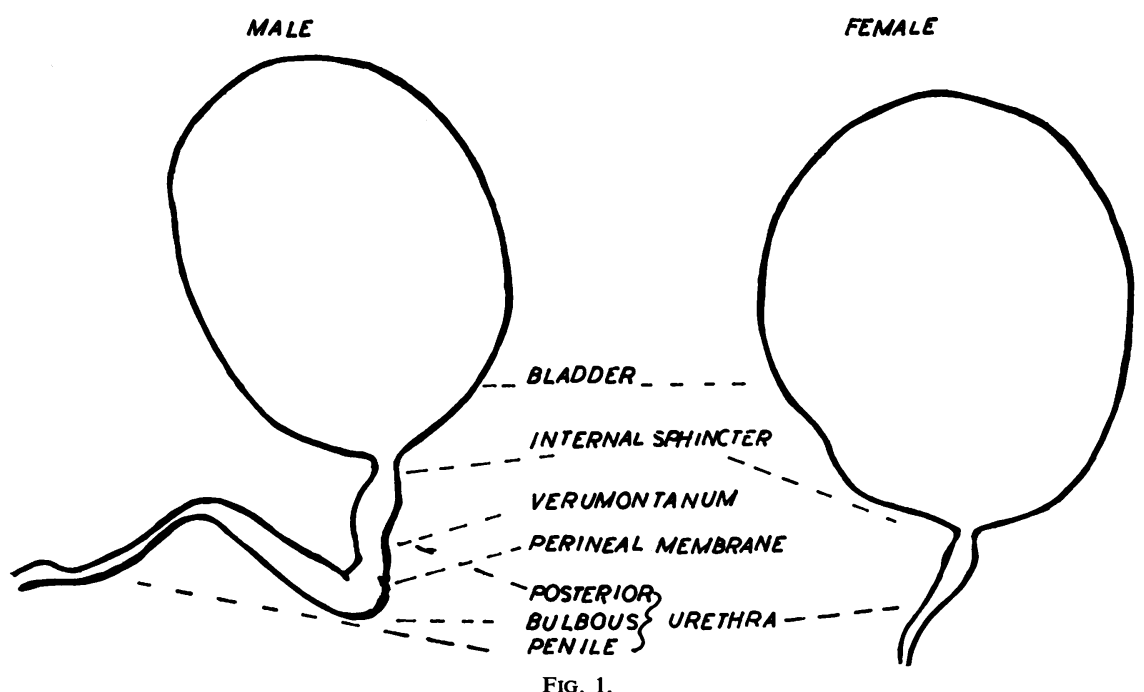

Fig. 1.

urine examined and cultured, and a micturating cysto-urethrogram carried out.

\section{Technique of Micturating Cysto-urethrography}

The patient was asked to empty the bladder and the act of micturition was observed. With aseptic precautions a rubber catheter was passed, and the patency of the external meatus and the ease of passage of the catheter through the urethra were noted. If an obstruction was encountered its distance from the external meatus was measured. If a rubber catheter could not be passed a fine ureteric catheter was tried. The amount of residual urine was recorded. A sterile $25 \%$ suspension of barium sulphate was injected slowly until the patient indicated the desire to micturate and then the capacity of the bladder was noted. The patient lay in the supine position with the left leg extended and the right hip joint flexed to an angle of 45 degrees. The pelvis was rotated about 35 degrees to the right, in order to obtain an oblique view of the urethra and base of the bladder. The $\mathrm{x}$-ray tube was rotated 5 degrees towards the patient's head so that the central ray was directed at right angles to the bladder outlet. Micturition was performed in successive stages and three or four exposures were made during the act of micturition.

Whenever an enlarged bladder or urethral obstruction was suspected clinically, or if the residual urine was greater than $30 \mathrm{ml}$. (1 ounce), a $12 \%$ diodone solution was used instead of barium sulphate, in order to avoid reflux of barium into the ureters and renal pelves.
Normal Appearances

Fig. 1 represents diagrammatically the normal outline of the male bladder and urethra during micturating cystourethrography. The bladder is smooth in outline but variable in shape; the internal sphincter causes a slight narrowing of the first part of the posterior urethra. Below this the verumontanum, if sufficiently large, may be shown as a spindleshaped filling defect $\frac{1}{2}-1 \mathrm{~cm}$. long. At the level of the perineal membrane the urethra may be constricted and this must not be confused with the filling defect of posterior urethral valves or congenital stenosis of the membranous urethra. Beyond this the anterior urethra widens in the bulbous portion and then narrows in the penile segment (Fig. 2). The bulbous urethra may overlap the membranous part if the pelvis is not sufficiently rotated laterally.

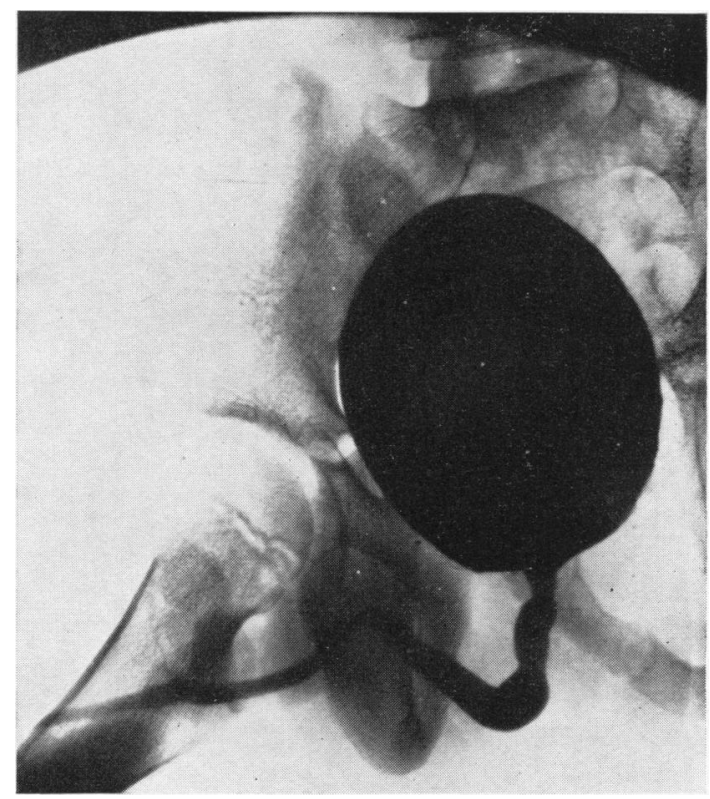

FIG. 2.-Micturating cysto-urethrogram of normal boy. 


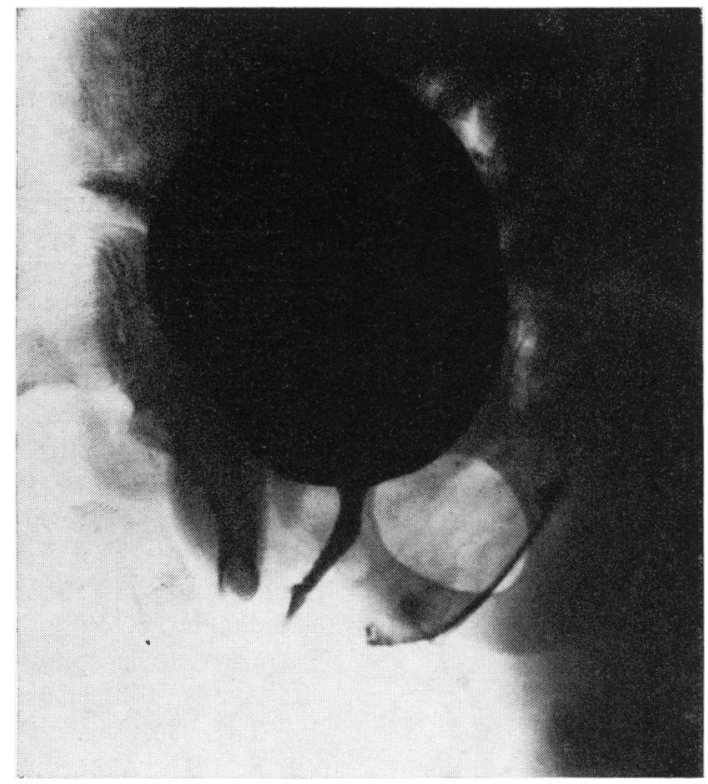

FIG. 3.-Micturating cysto-urethrogram of normal girl.

Fig. 1 also shows the normal outline of the female bladder and urethra; the internal sphincter causes a slight narrowing of the first part of the urethra, and below this there is a slight dilatation of the urethra which tapers towards the external meatus (Fig. 3).

\section{Bladder Capacity}

To determine the average bladder capacity, the relationship between bladder capacity and age was

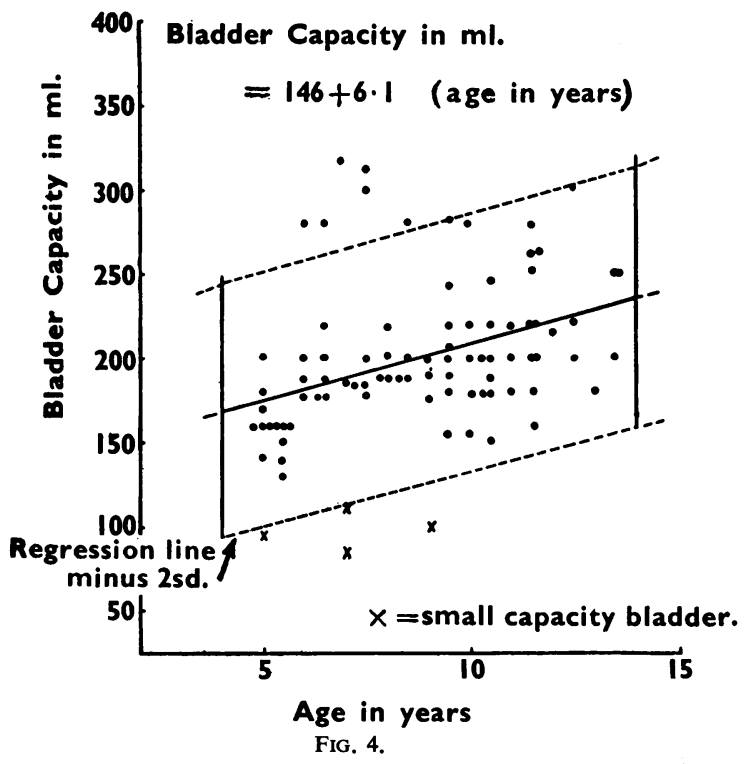

examined by fitting a linear equation of bladder capacity on age using 86 children with functional enuresis. The regression equation was:

Bladder capacity in $\mathrm{ml} .=146+6 \cdot 1$ (age in years), and the standard deviation from regression was $37 \cdot 7 \mathrm{ml}$. (Fig. 4). It should be emphasized that the above equation is limited to an age range of about 5 to 13 years.

\section{Findings}

In this series of 135 children with persistent enuresis 84 were boys and 51 girls; the age distribution of each sex is shown in Fig. 5. No organic disease or abnormality of the micturating cystourethrogram were found in 43 boys and 31 girls, and in these the enuresis was considered to be of functional origin. Of the 84 boys, 41 were abnormal, 25 with valves of the posterior urethra, one with stenosis of the membranous urethra; nine with a neurogenic disorder of the bladder and one with congenital hypertrophy of the bladder neck. There were two boys with small-capacity bladders, two with severe stenosis of the external meatus and one with a unilateral ureteral reflux without any associated anomaly. Of the 51 girls 20 were abnormal, three with a neurogenic disorder of the bladder and 14 with a wide bladder neck anomaly. There were two girls with small-capacity bladders and one with a unilateral ureteral reflux without any other detectable lesion.

The greater incidence of abnormalities in boys can be mainly attributed to the high proportion of posterior urethral valves which were the commonest disorder encountered in this series. This condition seldom occurs in girls.

\section{Congenital Valves of the Posterior Urethra}

According to Young, Frontz and Baldwin (1919) congenital valves of the posterior urethra may be classified anatomically into three main types according to their relation to the verumontanum, as shown in Fig. 6.

Type I shows bifurcated valves springing from the distal end of the verumontanum and passing downwards to the membranous urethra.

Type II (a) shows the valves arising proximal to the verumontanum. (b) The valves arise distal to the verumontanum from the wall of the urethra to form a diaphragm. (c) The valves arise from the verumontanum and pass to the wall of the urethra to form a diaphragm (according to Campbell, 1951).

Type III shows valves which may have up to seven leaves arising from the proximal end of the verumontanum and passing upwards to the bladder neck.

The clinical picture associated with posterior 
urethral valves will vary with the degree of obstruction. If this is very marked the newborn infant may present as a case of foetal ascites (Lord, 1953). If the obstruction is less severe the child develops the

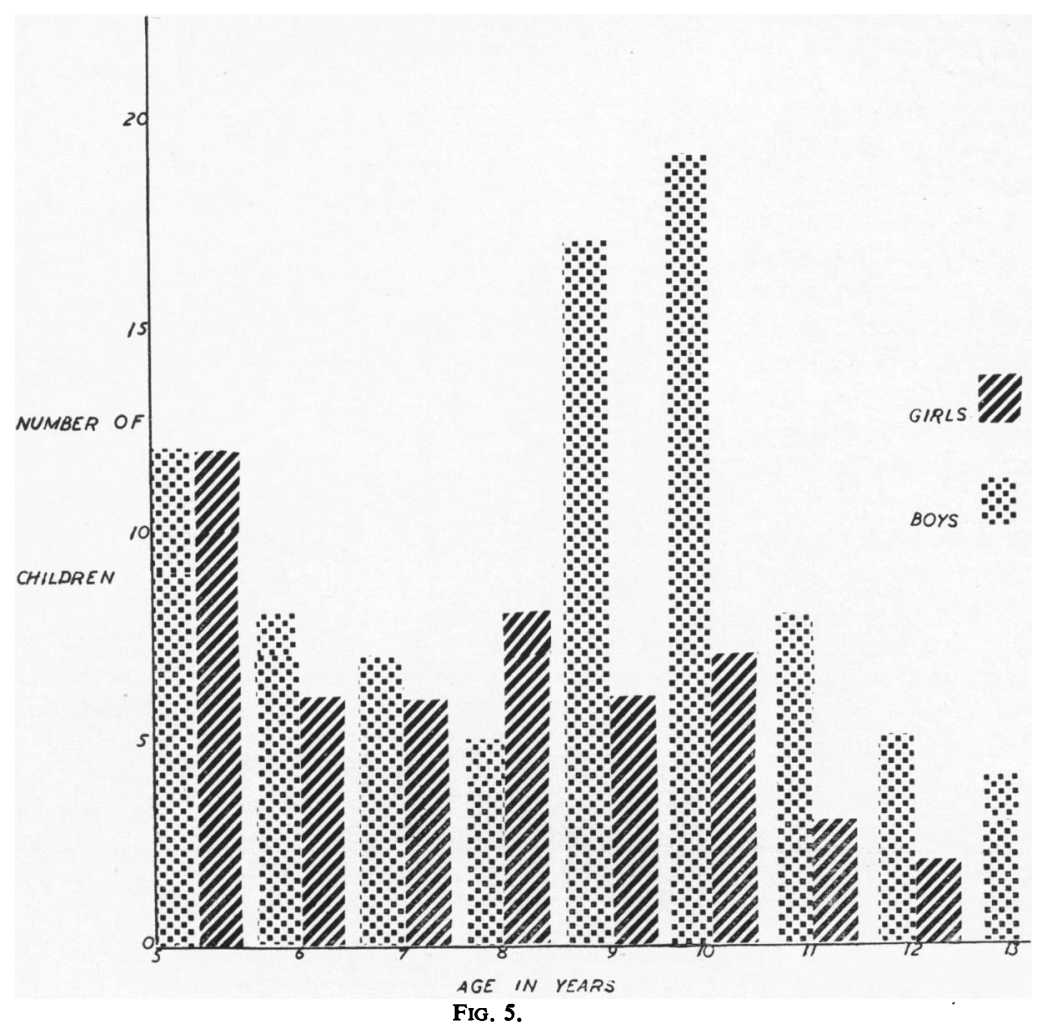

now, they are still considered to be rare. Regarding this point, Campbell (1951) states, 'Valvular obstruction of the urethra is not uncommon, it simply fails to be recognized. Most urologists will encounter one or more cases a year; this number represents only a small segment of the total incidence.'

We are in complete agreement with this, but consider that there is still another type of case in which urethral obstruction is unsuspected because of the lack of usual signs and symptoms. The child is usually between 4 and 12 years of age and shows no clinical evidence of enlargement of the bladder, retention of urine or impaired renal function. There is usually a history of frequency since birth and persistent nocturnal enuresis. The child is often continent during the day; we have observed that the enuresis may disappear and be replaced by persistent nocturnal frequency. It is important to realize that this change does not necessarily indicate that the patient is cured.

A review of the literature shows that some cases. may remain unrecognized until the third or fourth decade, when infection may supervene and they then present as persistent pyuria, recurrent pyelitis or chronic pyelonephritis. Infection may occur at an well-recognized clinical picture of vesical retention with an enlarged palpable bladder, dribbling incontinence, and difficult or hesitant micturition. There is usually evidence of impaired renal function and infection may supervene. The child is often retarded in growth and may even d e ve 1 op renal rickets.

In the past many such cases were diagnosed only a t necropsy, a nd a 1 though they are more readily recognized

POSTERIOR URETHRAL VALVES

TYPE 2

$A$

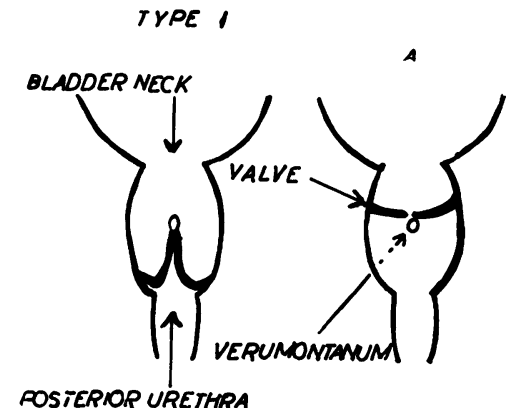

POSIERTOR URETHRA
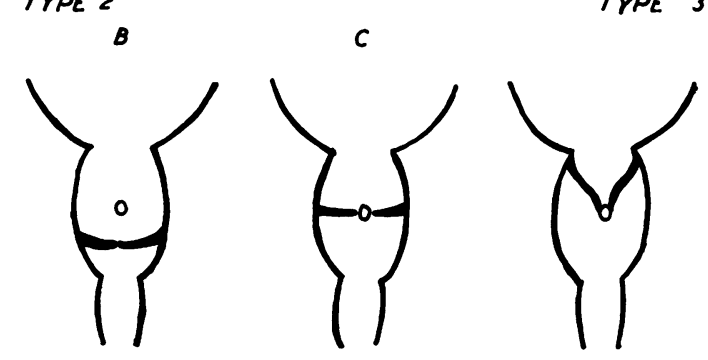

FIG. 6. 
earlier age but is not common unless the obstruction is severe or unless it is precipitated by instrumentation. It is possible for these patients to present later with impaired renal function or hypertension and the true nature of the malady may not be appreciated. It is therefore important to recognize and treat the disorder at the enuretic stage before irreparable damage to the urinary system is done.

The clinical picture presented by these 25 children with posterior urethral valves was as follows:

The enuresis was nocturnal in 14 , and nocturnal and diurnal in 11. The condition started in infancy in 20, and between 3 and 5 years in the remainder. Frequency was present in 19 and urgency in 12 . A history of dribbling was present in five children, and confirmed in three: of these three, two were noticed to strain on micturition. Straining was observed in two others, in one of whom dribbling was noted.

Faecal incontinence was present in five, and was associated with straining on micturition in two of these; the latter feature is important as it must be differentiated from faecal incontinence of neurogenic origin or secondary to chronic constipation.

A family history of enuresis was recorded in eight children, and subnormal intelligence in one. Examination of the urinary tract, which included palpation of the kidneys and bladder and inspection of the external genitalia, was normal, except for one child with hypospadias. The residual urine

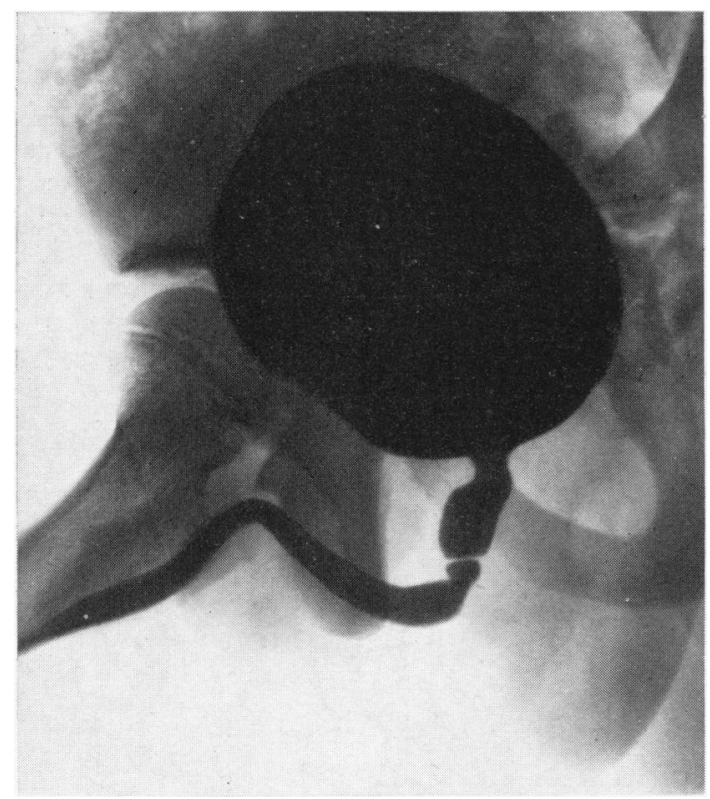

FIG. 7.-Micturating cysto-urethrogram showing filling defect due to posterior urethral valves.

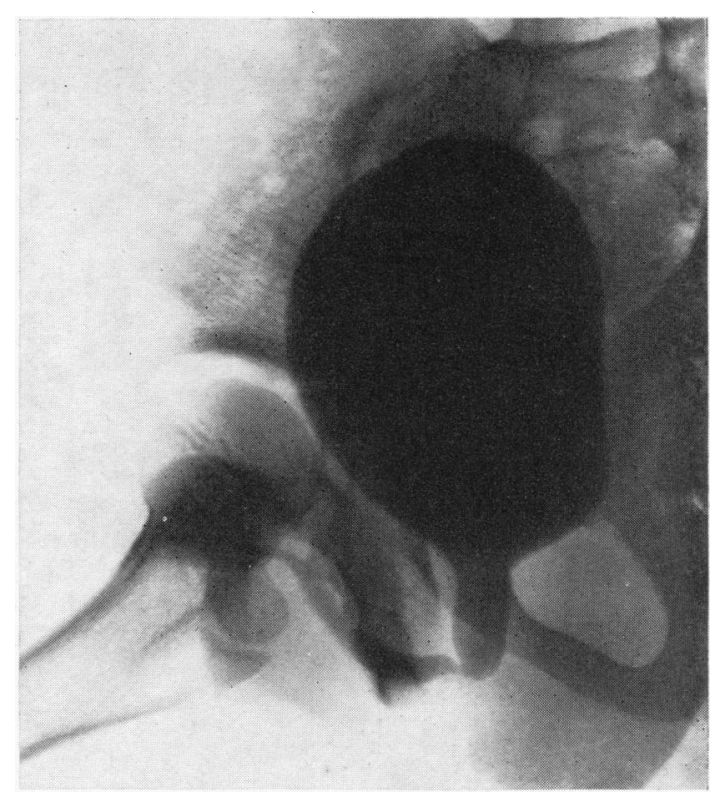

FIG. 8.-Micturating cysto-urethrogram showing marked dilatation of posterior urethra proximal to urethral valves.

never exceeded $20 \mathrm{ml}$., which suggests that at this stage the bladder could be emptied in spite of the obstruction. The bladder capacity varied from $80 \mathrm{ml}$. to $450 \mathrm{ml}$. In no case was the urine infected.

The diagnosis of a valvular malformation of the posterior urethra was made by micturating cysto-urethrography. In this investigation the valves showed as a constant constriction or filling defect in the posterior urethra (Figs. 7-9). The position of the valves varied, and they were seen in the upper, middle or lower third of the posterior urethra.

In the milder cases there was little dilatation of the posterior urethra above the valves, but as the obstruction became more severe the posterior urethra and internal sphincter widened (Figs. 8 and 9). Trabeculation of the bladder and diverticulum formation occurred and reflux into the ureter followed by hydronephrosis was also seen. In this series the presence and the location of the valves were confirmed by Mr. G. D. F. McFadden at urethroscopy.

Analysis of our cases shows no clear-cut clinical picture, although dribbling or straining on micturition are suggestive signs. It is important to observe the act of micturition to detect these signs, since some of our cases show that the history is unreliable, or the parents are unobservant. If reliance had been placed solely on the presence of dribbling or straining then 21 of our patients 


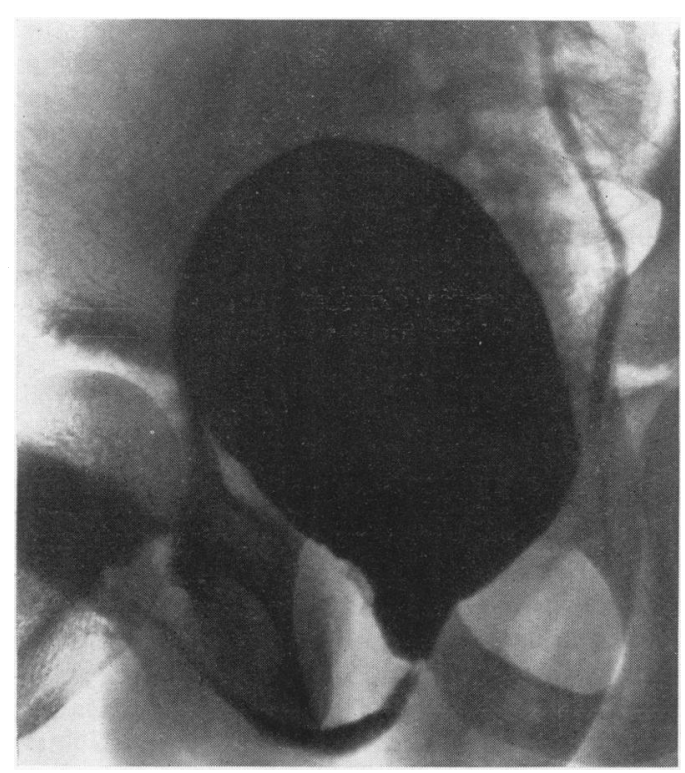

FIG. 9.-Micturating cysto-urethrogram showing marked dilatation of posterior urethra proximal to urethral valves and left ureteral reflux.

would not have been suspected or diagnosed at this early stage of the disease.

The diagnosis of this condition can be made easily by cysto-urethrography and although Campbell (1951) states that such valves may be readily visualized by urethroscopy, such proficiency and skill are exceptional. By the technique of micturating cysto-urethrography not only may the valves be demonstrated but they may be accurately localized and this is of great assistance to the surgeon during urethroscopy and operation.

\section{Neurogenic Disorders of the Bladder}

According to Uhle (1913), the internal vesical sphincter is of prime importance in bladder closure in man. In the paralysed bladder with typical funnelling of the bladder neck and urethra, the incontinence is due to dilatation of the internal sphincter and the urethral muscles and not to overflow or paradoxical bladder action. The weakness of the internal sphincter may be compensated by voluntary contraction of the muscles supporting the base of the bladder during the day. At night the muscles relax and incontinence occurs.

In the majority of cases of paralysed bladders there is evidence of neurological disease such as spina bifida with or without meningocoele, disseminated sclerosis, poliomyelitis, spinal cord tumours, etc. There is also a group in which a full neurological examination reveals no abnormality.
Nine boys and three girls in our series are considered to be of this type.

The clinical picture revealed that the enuresis was nocturnal and diurnal in all of the children except for one girl with nocturnal enuresis alone. Six boys had been normal for a varying period from $2 \frac{1}{2}$ to 9 years of age before enuresis ensued; in the remainder it began in infancy. Urgency was present in 10 children and frequency in eight; a history of dribbling was obtained in five and observed in three. Occasional faecal incontinence was present in six children and four had poor anal tone. A family history of enuresis was obtained from one child, another was mentally subnormal. There was no detectable clinical abnormality, motor or sensory, of the central nervous system in any case. The residual urine varied from 0 to $30 \mathrm{ml}$. and the bladder capacity from 120 to $960 \mathrm{ml}$. The urine was infected in two of these children. X-ray examination of the lumbar and sacral spine showed spina bifida in 10 of these children with splitting of the arch of the fifth lumbar vertebra in one boy and of the first sacral vertebra in eight boys and one girl.

Micturating cysto-urethrography revealed the characteristic smooth funnelling of the bladder outlet and urethra. In some cases, the bladder was greatly increased in capacity up to $960 \mathrm{ml}$; in others the bladder was contracted and trabeculated, and in one of these bilateral urethral reflux was observed towards the end of micturition (Figs. 10-12).

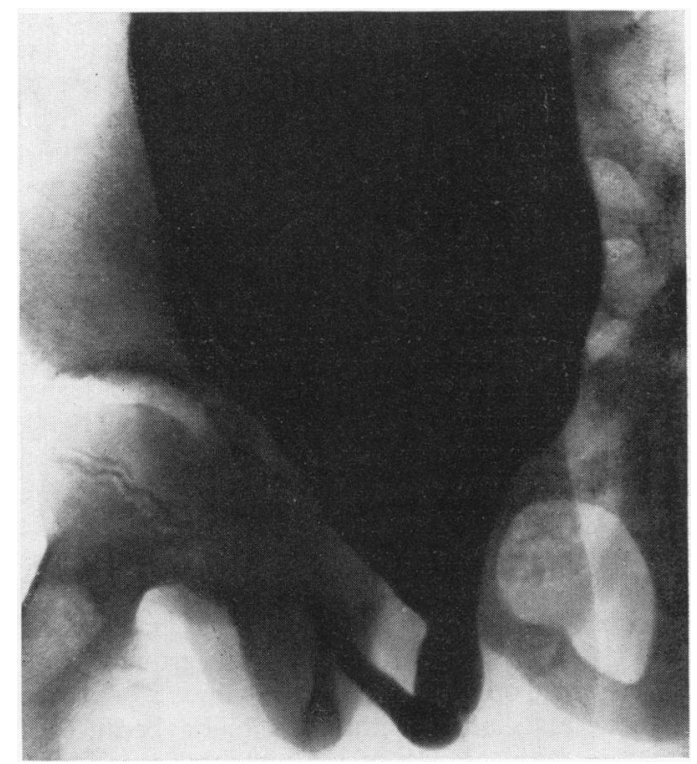

FIG. 10.-Micturating cysto-urethrogram showing enlarged bladder with paralytic funnelling of bladder neck and dilatation of posterior urethra. 


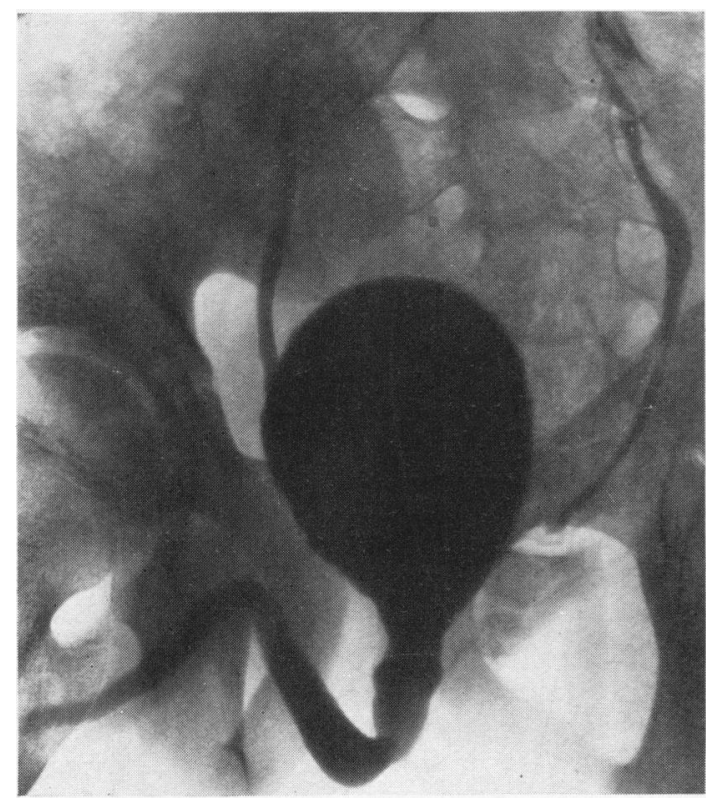

FIG. 11.-Micturating cysto-urethrogram showing paralytic bladder neck and bilateral ureteral reflux.

The marked dilatation of the posterior urethra and the non-functioning internal vesical sphincter were confirmed at urethroscopy and cystoscopy by Mr. McFadden.

Burns (1917) was the first to describe the characteristic funnelling of the bladder neck which is associated with bladder paralysis. He showed that the degree of funnelling depended on the amount of bladder distension and that it might become fixed and very wide in the contracted bladder with almost complete closure of the urethra at the external sphincter. However, in some of our patients the dilatation of the urethra was so gross that it extended beyond the external sphincter.

The examination of the central nervous system of these 12 children was normal except for poor anal tone in three, and the presence of a mild degree of spina bifida in 10. According to Riches (1944), although there may be only a mild degree of spina bifida occulta, the constant accompaniment of the typical cystoscopic picture leaves no doubt that the urinary symptoms are produced by it. Also it is noteworthy that the enuresis in five of the boys did not begin until after 5 years of age. Ingraham and Swan (1943) have shown that as a child grows tension may be placed on the spinal cord by a lipoma or fibrous tissue in association with spina bifida because of the more rapid growth of the vertebral canal compared with the spinal cord. This usually occurs between 6 and 10 years of age. About $50 \%$ of their cases of enuresis were cured by laminectomy, but those cases with only a mild degree of spina bifida did not improve following operation. However, Karlin (1935) states that 'spina bifida occulta can be considered as an organic basis for enuresis only in those cases which show an extensive involvement of the vertebrae in the lumbo-sacral region and also cases showing neurological signs'. The relationship between neurogenic disorder of the bladder and spina bifida requires further investigation.

From our series it is evident that a late onset of enuresis of a diurnal and nocturnal character, associated with urgency and frequency, dribbling without straining and occasional faecal incontinence, is suggestive of a neurogenic disorder of the bladder. However, this combination of symptoms and signs may also be observed in functional cases, and therefore micturating cysto-urethrography is essential in the diagnosis of this type of case especially as there are no abnormal neurological signs. The micturating cysto-urethrogram also provides a permanent record of the abnormality and this greatly facilitates the surgeon in the planning of operative treatment.

\section{Wide Bladder Neck Anomaly in Girls}

In addition to the three girls already described with a neurogenic disorder of the bladder, micturating cysto-urethrography revealed an abnormally wide bladder neck in a further 14 girls. This radiological finding, although somewhat variable, was

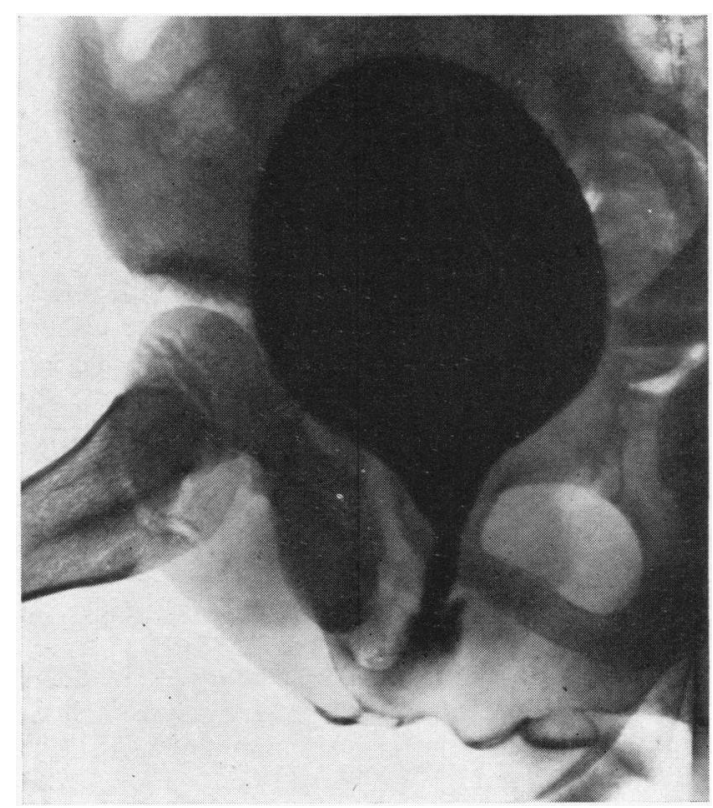

FIG. 12.-Micturating cysto-urethrogram of girl, showing paralytic funnelling of bladder neck. 
distinct from the smooth funnelling characteristic of a paralysed bladder neck.

The enuresis was nocturnal and diurnal in 11 and nocturnal in three. The condition began in infancy in seven and between 2 and 9 years of age in seven. Frequency and urgency were present in all but one. Only one child had occasional faecal incontinence, one was mentally subnormal and there was a family history of enuresis in four. The bladder capacity varied from 160 to $220 \mathrm{ml}$. and in four children there was a coliform infection of the urine. Rectal examination revealed that the anal tone was normal in all cases. Radiographs of the lumbar and sacral spines showed splitting of the arch of the first sacral vertebra in seven. However, three important points were noted: (1) Five girls gave a history of dribbling without straining. (2) One child had stress incontinence and her mother and grandmother suffered from the same disability from childhood. (3) No neurological disorder could be detected clinically.

Micturating cysto-urethrography demonstrated marked widening of the internal sphincter and upper part of the urethra. The urethra became normal in size at the external meatus and thus gave rise to the appearance of a spinning-top stuck to the base of the bladder (Figs. 13-14). A ureteral reflux was demonstrated in one patient at the beginning and end of micturition.

The cause of the wide bladder neck in girls is difficult to determine and there seem to be several

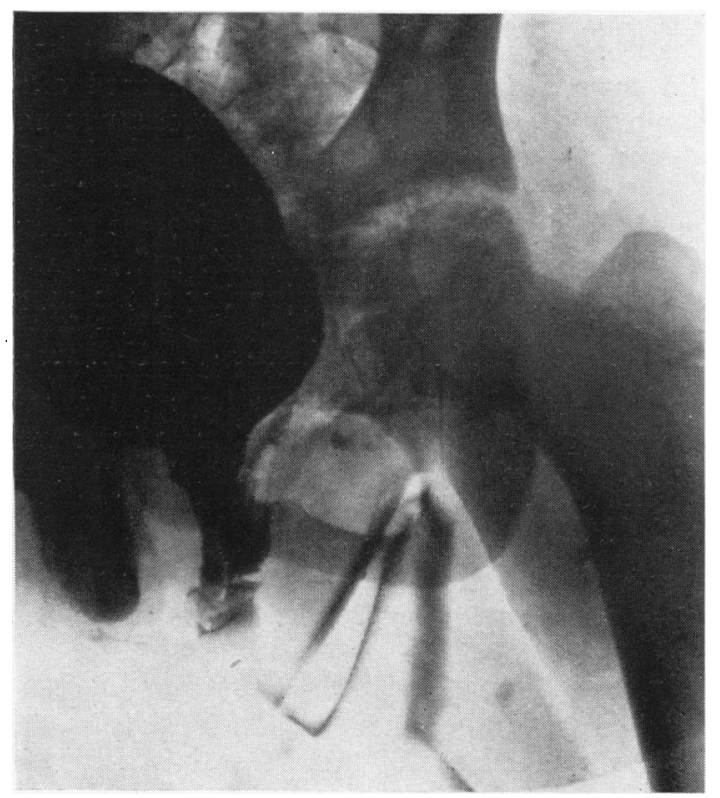

FIG. 13.-Micturating cysto-urethrogram showing wide bladder neck anomaly.

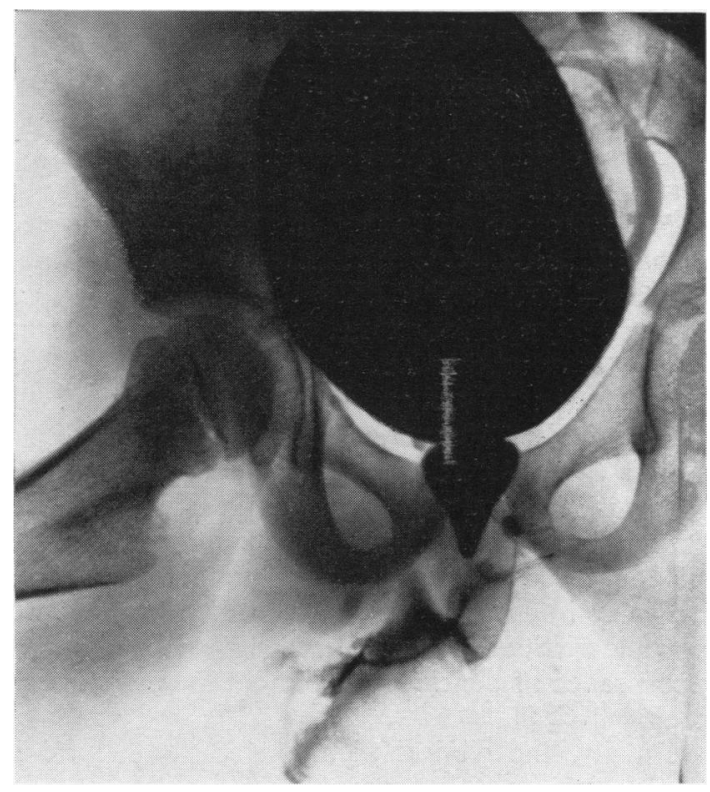

FIG. 14.-Micturating cysto-urethrogram showing wide bladder neck anomaly with unilateral ureteral reflux.

possible explanations: (a) Neurogenic disorder of the bladder, $(b)$ simple atony of the internal sphincter, (c) dilatation of the sphincter as a result of an infection or an obstruction in the urethra. The micturating cysto-urethrogram did not show the typical funnelling of a paralytic bladder and there were no abnormal neurological signs.

Campbell (1951) has demonstrated that children with chorea frequently develop a large atonic bladder; micturating cysto-urethrography undertaken in five children with chorea showed that the bladder capacity was increased above the normal average for their age, but there was no evidence of widening of the internal sphincter.

The most likely cause of an obstruction of the urethra, when foreign bodies and calculi are excluded, is either meatal stenosis or mucosal valves which have been described by Addison (1932). Difficulty was encountered on catheterization for cysto-urethrography in only one girl. The obstruction was considered to be due to marked meatal stenosis: this was confirmed and relieved at operation.

Addison (1932) in his description showed that the valves occur close to the external meatus. If this is the case then these valves may be very difficult to visualize by urethroscopy. In our cases which have been subjected to operation a catheter was passed down the urethra from the bladder without encountering an obstruction, except in the patient with meatal stenosis. 
It is well known that chronic inflammation of the bladder may give rise to dilatation and impaired function of the uretero-vesical sphincters. It seems reasonable to assume that a similar dilatation may occur at the internal vesical sphincter. Four of our cases had a urinary infection, and although the infection responded to treatment enuresis persisted. At urethroscopic examination before operation none of the children with a wide bladder-neck anomaly showed signs of inflammation around the internal sphincter or urethra, and therefore it seems unlikely that infection was responsible for the dilatation.

In a study of enuretic children, Campbell (1934) found that urethro-trigonitis was the commonest lesion in girls and often occurred in boys. We have found that in children with inflammation around the bladder neck, micturating cysto-urethrography is of no value in detecting the condition. However, if a chronic cystitis is present, fuzziness or a moth-eaten appearance of the cystographic outline is frequently seen.

Finally, the clinical picture was not helpful in distinguishing this group from children with functional enuresis, although dribbling without straining and the presence of stress incontinence were suggestive. It is therefore impossible to separate this group from the functional cases without cysto-urethrography.

\section{Small Capacity Bladder}

Vesical spasm is common in childhood and may be attributed to reflex causes such as vesical or urethral inflammation, calculi, or rectal disturbance such as anal fissure.

There is, however, a small group of children who have a very limited bladder capacity in whom no such cause can be detected. This condition resembles the high tension bladder of infancy and results in frequency, urgency, precipitate micturition and enuresis. Two boys and two girls were considered to be of this type.

The clinical picture revealed that the enuresis was nocturnal in the boys and nocturnal and diurnal in the girls. Three started in infancy and one boy at 3 years of age. Frequency was present in two boys and one girl, and urgency in one boy and two girls. One of the girls was mentally subnormal and the other had a urinary infection.

Micturating cysto-urethrography demonstrated on repeated examination that the bladder capacities fell below the normal average for their ages (Fig. 4). All of these children were typical in showing great discomfort when the bladder reached its maximum capacity which varied from 90 to $120 \mathrm{ml}$. This was followed by explosive or uncon- trollable micturition. The cysto-urethrogram showed a small bladder with a smooth outline and a normal urethra.

As no local cause could be found for the condition it was probably due to a failure of physiological development. The cysto-urethrogram was normal, which distinguishes this condition from the hypertonic spastic bladder where there is a constriction at the internal sphincter and frequently bladder trabeculation.

\section{Meatal Stenosis}

Stenosis of the external meatus may be congenital or acquired and the degree of obstruction is variable. If it is slight, the patient may complain of dysuria and pass urine in a fine or intermittent stream. If severe, fatal retention may occur and this has been recorded by Higgins, Williams and Nash (1951). Four boys and one girl were found to have this disorder. The girl had an associated wide bladder-neck anomaly and was considered above. One of the boys with a pinhole meatus and a second degree hypospadias was subsequently found to have hypertrophy of the internal vesical sphincter and this will be discussed below. Another boy with a valvular anomaly has been included with the 25 cases of posterior urethral valves. Two boys remain to be considered.

The clinical picture revealed that the enuresis was nocturnal in one and nocturnal and diurnal in the other. One complained of frequency and urgency, but neither gave a history of dysuria. The symptoms were present from infancy in both and in one case the symptoms developed after circumcision. In both cases the stenosis was not seen on inspection.

During micturating cysto-urethrography it was found that a rubber catheter could not be passed into the urethra and a fine ureteric catheter was used instead. When micturition began the urine was expelled in a fine stream.

The diagnosis of meatal stenosis is usually made by inspection, but in these two boys the condition was not evident until a rubber catheter was used. Stockwell and Smith (1940) described 23 cases of meatal stenosis in a series of 100 children with enuresis but they thought that in only three of these it was the primary cause. One of our patients was cured by meatotomy, but the other is unchanged.

\section{Congenital Stenosis of the Membranous Urethra}

This is an uncommon condition and in the absence of a history of trauma or infection it is likely to be congenital in origin. One boy showed this malformation. His enuresis, which started in 
infancy, was nocturnal and diurnal. Frequency and urgency were present and there was a history of straining during micturition which was associated with occasional faecal incontinence.

Before micturating cysto-urethrography, passage of the rubber catheter was prevented by an obstruction $7.5 \mathrm{~cm}$. from the external meatus. A fine ureteric catheter was passed successfully and the cysto-urethrogram showed marked dilatation of the posterior urethra and internal sphincter proximal to the obstruction. A large diverticulum was present on the left side of the bladder (Fig. 15).

\section{Congenital Hypertrophy of the Vesical Outlet}

A review of the literature has shown that some of these cases, like those of valvular anomalies, may remain unrecognized until the second or third decade. Congenital hypertrophy of the vesical outlet may be associated with meatal stenosis or stenosis at the uretero-vesical junction. Campbell (1930) drew attention to the similarity of this condition and congenital hypertrophy of the pylorus. One of the boys showed this anomaly which was associated with pinhole meatal stenosis and second degree hypospadias.

His enuresis began in infancy and was nocturnal and diurnal. Marked frequency was present and the child complained of difficulty in passing urine.

The pinhole meatus was easily recognized but there was no evidence of distension of the penile urethra behind the obstruction and it was thought there must be an obstruction higher up. Micturating cysto-urethrography showed that the supracollicular portion of the urethra was elongated

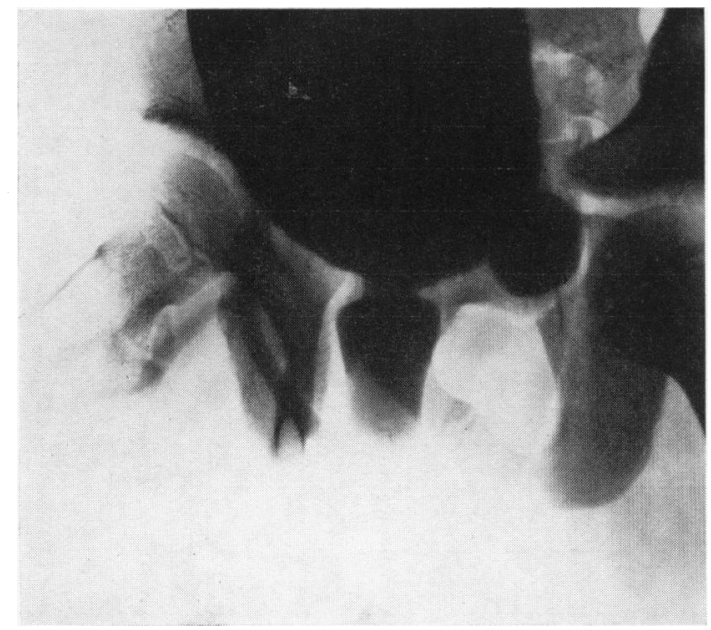

FIG. 15.-Micturating cysto-urethrogram showing marked dilatation of posterior urethra proximal to stenosis of membranous urethra. Note bladder diverticulum.

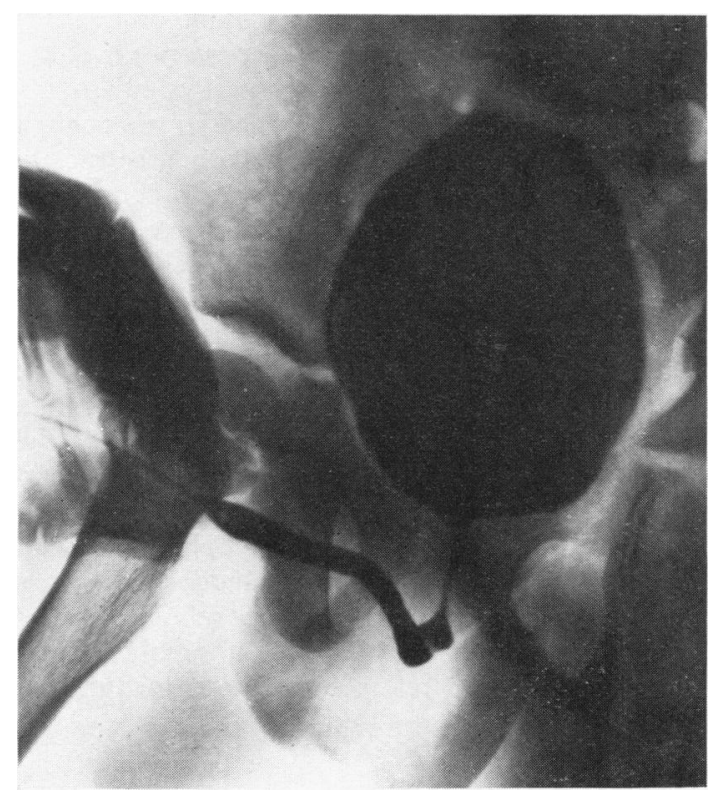

FIG. 16.-Micturating cysto-urethrogram showing narrowing of posterior urethra due to congenital hypertrophy of bladder neck. Note dilatation of urethra proximal to the meatal stenosis and the fine ejection stream.

and compressed (Fig. 16). Towards the end of micturition a left ureteral reflux was observed. At operation the hypertrophied sphincter was palpated rectally when a urethral dilator was inserted. Following operative treatment the enuresis disappeared.

Congenital hypertrophy and congenital contracture of the internal sphincter are probably variations of the same condition. Brodny and Robins (1944) have shown in the latter condition that the internal sphincter is shortened and constricted and the bladder base flattened. In congenital hypertrophy of the vesical outlet the internal sphincter forms a collar-like structure which projects into the floor of the bladder, giving rise to a concave filling defect. It compresses and elongates the urethra at this level.

\section{Uretero-Vesical Reflux}

Bell (1812) demonstrated that the intramural part of the ureter was compressed and had a more competent valvular action when the bladder was distended than when it was contracted and the ureter was less oblique. In 1925 Graves and Davidoff showed by experiments on cats, dogs and rabbits that ureteral reflux depends primarily upon the sustained tonus of the bladder; that is, reflux never occurs when the active sustained contraction is lack- 
ing, e.g. in a paralytic bladder. Young et al. (1919) observed in some of their cases of posterior urethral valves and in other reported cases that when the ureters communicate with the bladder through a large orifice the bladder was usually contracted. Riches (1943) recorded in his cases with neurogenic disorders of the bladder that the ureteral reflux occurs towards the end of micturition.

In this series, five children showed radiological evidence of ureteral reflux towards the end of micturition. The reflux was not found when the bladder was distended. A bilateral ureteral reflux was associated with a neurogenic disorder of the bladder in one case. Two patients with unilateral reflux were seen in association with valvular anomaly of the posterior urethra. The child with congenital hypertrophy of the bladder neck was found to have a unilateral ureteral reflux. One of the girls with a wide bladder-neck anomaly showed a unilateral ureteral reflux throughout micturition.
It may be that the uretero-vesical valve was dilated by a similar mechanism as the internal vesical sphincter.

In another boy and girl no abnormality was found to account for the reflux; although the girl had a urinary infection this was not thought to be the primary cause. The significance of vesico-ureteral reflux is debatable in these two cases. Campbell (1951) states that he has never observed it in the absence of demonstrable urological disease. However, Gibson (1949) recorded two cases in a series of 43 children in whom the urinary tract was apparently normal, but we note that cystoscopy was not undertaken.

\section{Functional Enuresis}

As no organic disease or abnormality of the micturating cysto-urethrogram were found in 43 boys and 31 girls their enuresis was considered to be of functional origin. However, five of these

\begin{tabular}{|c|c|c|c|c|c|c|c|c|c|c|c|c|c|}
\hline \multirow[t]{2}{*}{ Type of Case } & \multicolumn{2}{|c|}{ 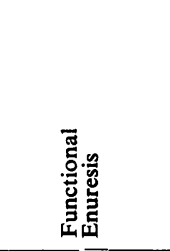 } & \multicolumn{2}{|c|}{ 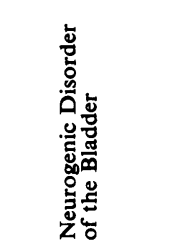 } & \multicolumn{2}{|c|}{ 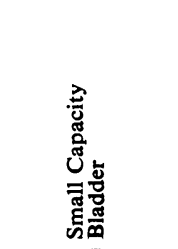 } & \multirow[t]{2}{*}{ 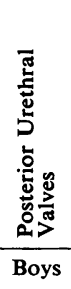 } & \multirow[t]{2}{*}{ 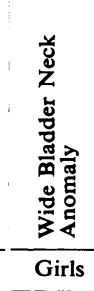 } & \multirow[t]{2}{*}{ 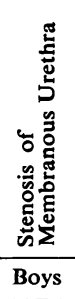 } & \multirow[t]{2}{*}{ 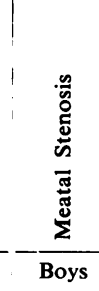 } & \multirow[t]{2}{*}{ 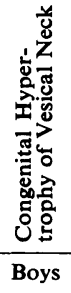 } & \multicolumn{2}{|c|}{ 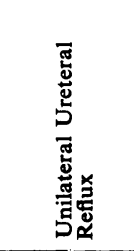 } \\
\hline & Boys & Girls & Boys & Girls & Boys & Girls & & & & & & Boys & Girls \\
\hline Number of cases & 43 & 31 & 9 & 3 & 2 & 2 & 25 & 14 & 1 & 2 & 1 & 1 & 1 \\
\hline $\begin{array}{l}\text { With onset in } \\
\text { infancy } \ldots\end{array}$ & 34 & 20 & 3 & 3 & 1 & 2 & 20 & 7 & 1 & 2 & 1 & - & 1 \\
\hline $\begin{array}{l}\text { Nocturnal } \\
\text { enuresis ... }\end{array}$ & 32 & 14 & - & 1 & 2 & - & 14 & 3 & 一 & 1 & 一 & 1 & 1 \\
\hline $\begin{array}{l}\text { Nocturnal and } \\
\text { diurnal .. }\end{array}$ & 11 & 17 & 9 & 2 & - & 2 & 11 & 11 & 1 & 1 & 1 & - & - \\
\hline Frequency & 14 & 16 & 6 & 2 & 2 & 1 & 19 & 13 & 1 & 1 & 1 & - & 1 \\
\hline Urgency . . & 14 & 19 & 8 & 2 & 1 & 2 & 12 & 13 & 1 & 1 & - & - & 1 \\
\hline $\begin{array}{l}\text { History of } \\
\text { dribbling }\end{array}$ & 2 & 2 & 5 & - & - & - & 5 & 5 & 1 & 1 & 1 & - & - \\
\hline Straining & 一 & - & - & 一 & - & 一 & 2 & - & 1 & - & 一 & 一 & 一 \\
\hline $\begin{array}{l}\text { Faecal Incon- } \\
\text { tinence } \ldots \\
\end{array}$ & 6 & 2 & 6 & 一 & 一 & - & 5 & 1 & 1 & - & 1 & 一 & - \\
\hline $\begin{array}{l}\text { Family history of } \\
\text { enuresis .. }\end{array}$ & 20 & 9 & 1 & 一 & - & - & 8 & 4 & 1 & - & - & 1 & - \\
\hline Subnormal I.Q. & 1 & 4 & 1 & - & 一 & 1 & 1 & 1 & 一 & - & - & - & - \\
\hline $\begin{array}{l}\text { Observed } \\
\text { dribbling }\end{array}$ & 一 & 一 & 3 & - & - & 一 & 4 & 一 & 1 & 一 & 1 & 一 & 一 \\
\hline $\begin{array}{l}\text { Observed } \\
\text { straining . . }\end{array}$ & 一 & - & - & 一 & - & 一 & 4 & - & 1 & - & - & 一 & - \\
\hline Poor anal tone .. & 3 & 2 & 3 & 1 & 一 & 一 & 1 & - & 一 & - & 1 & 一 & - \\
\hline Urinary infection & - & 5 & 2 & 一 & 一 & 1 & 一 & 4 & - & - & - & - & 1 \\
\hline
\end{tabular}


children were found to have a urinary infection; in four the urine contained no pus cells but coliform organisms were present; in the other there was a pyuria due to $B$. proteus. Although the infection responded to treatment in all, the enuresis persisted.

When this investigation was initiated the relevant signs and symptoms were recorded as it was hoped that separate clinical patterns would be determined for each aetiological group. These are recorded in the table, and from this it can be seen that the clinical picture was so varied in the functional group that it could not be distinguished from the organic conditions.

\section{Summary and Conclusion}

One hundred and thirty-five children with persistent enuresis were investigated by micturating cysto-urethrography.

In 43 boys and 31 girls the enuresis was considered to be of functional origin.

In 41 boys and 20 girls this procedure revealed abnormalities of the urinary tract. These included valves of the posterior urethra (25), neurogenic disorders of the bladder (12), wide bladder-neck anomaly (14), small capacity bladder (four), meatal stenosis (two), ureteral reflux (2), stenosis of the membranous urethra (one) and congenital hypertrophy of the vesical neck (one).

The symptoms and signs of the organic disorders did not distinguish them from the functional enuretics.

The radiological technique is simple enough to be undertaken in any radiographic department and it causes no more disturbance to the child then catheterization.

It is our opinion that micturating cysto-urethrography is an essential investigation for the detection of organic disorders of the urinary tract in children with persistent enuresis.

We acknowledge with gratitude the advice and encouragement of Professor F. M. B. Allen, and the skill and experience of Mr. G. D. F. McFadden who performed the urological examinations.

We wish to thank the medical, radiological and nursing staffs of the Royal Belfast Hospital for Sick Children and the Ulster Hospital for Children and Women for their invaluable co-operation.

\section{REFERENCES}

Addison, O. (1932). Archives of Disease in Childhood, 7, 25. Bell, C. (1812). Med.-Chir. Trans. Lond., 3, 171.

Brodny, M. L. and Robins, S. A. (1944). J. Amer. med. Ass., 126, 1000 .

Burns, J. E. (1917). Surg. Gynec. Obstet., 24, 659.

Campbell, M. F. (1930). J. Amer. med. Ass., 94, 1373. - (1934). N.Y.St. J. Med., 34, 190.

(1951). Clinical Pediatric Urology. Philadelphia.

Cohen, D. L. (1947). J. Urol., Baltimore. 57, 331.

Despert, J. L. (1944). Psychomat. Med., 6, 294.

Gibson, H. M. (1949). J. Urol., Baltimore, 62, 40.

Graves, R. C. and Davidoff, L. M. (1925). Ibid., 14, 1.

Higgins, T. T., Williams, D. I. and Nash, D. F. E. (1951). The Urology of Childhood. London.

Ingraham, F. D. and Swan, H. (1943). New Engl. J. Med., 228, 559.

Karlin, I. W. (1935). Amer. J. Dis. Child., 49, 125.

Lord, J. M. (1953). Archives of Disease in Childhood, 28, 398.

Riches, E. W. (1943). Brit. J. Surg., 31, 135

- (1944). Proc roy Soc Med 37, 77.

Sheldon, W. (1944). Ibid., 37, 348.

Stockwell, L. and Smith, C. K. (1940). Amer. J. Dis. Child., 59, 1013. Thorne, F. C. (1944). Amer. J. Psychiat., 100, 686.

Uhle, A. A. (1913). Trans. Amer. Ass. gen.-urin. Surg., 8, 303.

Young, H. H. Frontz, W. A. and Baldwin, J. C. (1919). J. Urol., Baltimore, 3, 289. 